\title{
Resupply of mesopelagic dissolved iron controlled by particulate iron composition
}

\author{
Bressac M. 1, 2, ${ }^{*}$, Guieu C. 2, 3, Ellwood M. J. ${ }^{4}$, Tagliabue A. ${ }^{5}$, Wagener T. 6 , \\ Laurenceau-Cornec E. C. ${ }^{1}$, Whitby Hannah ${ }^{7}$, Sarthou Geraldine ${ }^{9}$, Boyd P. W. 1,8
}

${ }^{1}$ Institute for Marine and Antarctic Studies, University of Tasmania, Hobart, Tasmania, Australia

2 Sorbonne Université, CNRS, Laboratoire d'Océanographie de Villefranche, LOV, Villefranche-sur-Mer, France

${ }^{3}$ The Center for Prototype Climate Modeling, New York University in Abu Dhabi, Abu Dhabi, United

Arab Emirates

${ }^{4}$ Research School of Earth Sciences, Australian National University, Canberra, Australian Capital

Territory, Australia

${ }^{5}$ Department of Earth Ocean and Ecological Sciences, School of Environmental Sciences, University of Liverpool, Liverpool, UK

${ }^{6}$ Aix Marseille Université, CNRS, IRD, Université de Toulon, MIO UM 110, Marseille, France

7 UMR 6539/LEMAR/IUEM, CNRS, UBO, IRD, Ifremer, Technopôle Brest Iroise, Plouzané, France

${ }^{8}$ Antarctic Climate and Ecosystems Collaborative Research Center, University of Tasmania, Hobart,

Tasmania, Australia

9 UMR 6539/LEMAR/IUEM, CNRS, UBO, IRD, Ifremer, Technopôle Brest Iroise, Plouzané, France

* Corresponding author: M. Bressac, email address : matthieu.bressac@utas.edu.au

\begin{abstract}
:
The dissolved iron supply controls half of the oceans' primary productivity. Resupply by the remineralization of sinking particles, and subsequent vertical mixing, largely sustains this productivity. However, our understanding of the drivers of dissolved iron resupply, and their influence on its vertical distribution across the oceans, is still limited due to sparse observations. There is a lack of empirical evidence as to what controls the subsurface iron remineralization due to difficulties in studying mesopelagic biogeochemistry. Here we present estimates of particulate transformations to dissolved iron, concurrent oxygen consumption and iron-binding ligand replenishment based on in situ mesopelagic experiments. Dissolved iron regeneration efficiencies (that is, replenishment over oxygen consumption) were 10- to 100-fold higher in low-dust subantarctic waters relative to higher-dust Mediterranean sites. Regeneration efficiencies are heavily influenced by particle composition. Their make-up dictates ligand release, controls scavenging, modulates ballasting and may lead to the differential remineralization of biogenic versus lithogenic iron. At high-dust sites, these processes together increase the iron remineralization length scale. Modelling reveals that in oceanic regions near deserts, enhanced lithogenic fluxes deepen the ferricline, which alter the vertical patterns of dissolved iron replenishment, and set its redistribution at the global scale. Such wide-ranging regeneration efficiencies drive different vertical patterns in dissolved iron replenishment across oceanic provinces.
\end{abstract}


44 Globally, the productivity of major phytoplankton groups, including diatoms and diazotrophs,

45 is set by dissolved iron (DFe) supply ${ }^{1}$. Twenty years of research has revealed diverse modes

46 of DFe supply, from dust to hydrothermal vents, and their regional influences ${ }^{2,3}$. Iron

47 biogeochemistry is a rapidly evolving field, driving the development of global modelling

48 initiatives ${ }^{4}$. However, iron cycling in the oceans' interior, a fundamental component of iron

49 biogeochemistry ${ }^{5,6}$, represents a major unknown, and critically is hindering model 50 development ${ }^{7}$. 
52 Deep winter mixing is a key vector in the annual resupply of upper ocean DFe stocks ${ }^{8}$. At 53 depth, DFe is replenished via biotic (e.g., microbial solubilization) and abiotic (e.g., 54 dissolution) transformations (also termed remineralization or replenishment here) of 55 particulate $\mathrm{Fe}(\mathrm{PFe})^{7}$. To date, internal iron cycling has been investigated using three 56 distinctive approaches, each of which has improved it's representation in biogeochemical 57 models $^{9-11}$. Firstly, studies deploying trace metal-clean multi-depth sediment traps, in regions 58 dominated by biogenic PFe, provided initial evidence of subsurface decoupling in PFe 59 remineralization relative to phosphorus $(\mathrm{P})$, carbon $(\mathrm{C})$ or nitrogen ${ }^{12-15}$. Second, bacterially60 mediated PFe remineralization - suppressed in sediment trap studies due to preservatives 61 was investigated in shipboard time-series incubations of resuspended mesopelagic particles in 62 which the release of DFe and Fe-binding ligands resulted from particle degradation ${ }^{9,16}$. Third, 63 dust addition experiments within nearshore $15 \mathrm{~m}$ deep mesocosms demonstrated that 64 lithogenic Fe, conventionally viewed as a major source of external Fe to surface waters ${ }^{1,2,17}$, 65 can either release (dissolution) or remove (scavenging) DFe depending on the initial 66 biogeochemical conditions ${ }^{18-20}$.

These three approaches to internal iron cycling targeted different processes, such as ligand and DFe release $\mathrm{P}^{9,16}$, patterns in PFe flux attenuation ${ }^{12-15}$, or scavenging and dissolution ${ }^{18-20}$.

70 However, it is difficult to compare the findings of these studies as they each sampled particle 71 assemblages with differing contributions from biogenic and lithogenic iron. Hence, no study 72 so far has examined the relative role of the different processes associated with biogenic versus 73 lithogenic Fe on internal iron cycling. The hypothesis ${ }^{9}$ that the composition of particles will 74 largely determine mesopelagic patterns of DFe replenishment remains untested due to 75 difficulties in studying this stratum ${ }^{21}$ and in discriminating between biogenic and lithogenic 
PFe within sinking particles ${ }^{7}$. Here, we overcame both limitations by targeting regions dominated by biogenic, a mix of biogenic/lithogenic, or lithogenic sinking PFe, and applying a novel in situ particle interceptor/incubator - RESPIRE ${ }^{22}-$ to iron biogeochemistry to concurrently elucidate the roles of biogenic and lithogenic PFe and their fate within the upper mesopelagic zone ( 100-200 m depth).

Contrasting biogeochemical areas - Mesopelagic Fe cycling was studied using a trace metal-clean version of RESPIRE (TM-RESPIRE; Supplementary-Fig. 1) on a surfacetethered free-drifting mooring to non-intrusively intercept settling particles, and then immediately (i.e., at the end of the 1-2 d collection period) incubate them within this device at in situ pressure and temperature. RESPIRE ${ }^{22}$ provides rates of remineralization by particleattached bacteria based on an oxygen consumption time-series (Fig. 1a-b). TM-RESPIRE provides the $\mathrm{PFe} / \mathrm{P} / \mathrm{C}$ sinking fluxes and associated $\mathrm{DFe} / \mathrm{P} / \mathrm{C}$ replenishment rates along with concurrent release of iron-binding ligands. In doing so, the TM-RESPIRE approach (along with subsequent analysis to estimate scavenging) combines all three previous approaches and permits the investigation in situ of the different processes driving the Fe remineralization and their interplay.

RESPIRE and TM-RESPIRE were deployed (vertically separated by $<20 \mathrm{~m}$; Methods) at 1 or 2 depths in the upper mesopelagic (110-200 m depth) during GEOTRACES process studies in the Subantarctic Zone (SAZ) and Mediterranean Sea (Supplementary-Table 1; Methods). These sites span wide-ranging dust deposition and productivity regimes (Fig. 1c). At SAZ, High-Nitrate-Low-Chlorophyll (HNLC) surface waters are characterized by low dust deposition and biologically-limiting DFe levels ${ }^{24}$. In contrast, Fe-rich oligotrophic waters of the Eastern Mediterranean (ION site) encounter intense Saharan dust deposition event ${ }^{23}$. In 
addition, a site within the Algerian basin (Western Mediterranean, ALG site) was selected

102 since it had intermediate characteristics between these end-members (Fig. 1c).

104 These site-specific characteristics were reflected in the widely-differing particulate organic 105 carbon (POC) and PFe sinking fluxes (Fig. 2; Supplementary-Table 1). SAZ had low POC

106 fluxes (0.9-1.2 mmol m $\left.\mathrm{m}^{-2} \mathrm{~d}^{-1}\right)$, but in contrast to the seasonal biological trends evident in Fig.

107 1c, 4-fold higher POC fluxes were measured at ION and ALG relative to SAZ, suggesting 108 that a higher proportion of productivity was exported at these higher dust sites. This trend was 109 probably due to lithogenic ballasting which is often associated with a high proportion of the

110 POC export in the Mediterranean $\mathrm{Sea}^{25,26}$. PFe fluxes at the Mediterranean sites were also $111 \sim 15$-fold higher $\left(8.0-12.5 \mu \mathrm{mol} \mathrm{m}^{-2} \mathrm{~d}^{-1}\right.$ at $115 \mathrm{~m}$ depth) relative to the Subantarctic. This 112 order-of-magnitude difference was driven by dust-derived lithogenic material

113 (Supplementary-Fig. 2b and f), a major constituent of Mediterranean sinking fluxes ${ }^{26}$ but 114 negligible at $\mathrm{SAZ}^{27}$. Indeed, the $\mathrm{Fe} / \mathrm{C}$ ratio of the sinking particles, a proxy of the 115 biogenic:lithogenic PFe (Methods), ranged $>30$-fold $(\sim 460-13970 \mu \mathrm{mol} / \mathrm{mol})$ confirming the 116 SAZ site as the low lithogenic Fe end member (Fig. 3b-c). At ALG and ION, contrasting POC

117 and PFe flux attenuation patterns were evident, with PFe increasing with depth while a 3-fold 118 attenuation of POC flux occurred between 115-195 m depth (Fig. 2). Consequently, a 119 decrease in the relative proportion of biogenic PFe occurred over this stratum, evident by 120 increased Fe/C ratios (Fig. 3b-c).

121

122 Mesopelagic bacterial remineralization - Oxygen-based remineralization rates were 123 correlated linearly to the POC concentrations within the RESPIRE (i.e., the intercepted POC 124 flux; Fig. 3a). The absence of significant relationship(s) with other flux characteristics 125 (Supplementary-Fig. 2a-d), reveals that POC exerted a first-order control on remineralization 
rates. To assess whether DFe replenishment is largely driven by microbial solubilization of

127 biogenic Fe in settling particles, we investigated trends in Fe regeneration efficiency $\left(R_{\mathrm{Fe} / \mathrm{O} 2}\right)$.

128 Both site-specific and water-column processes contributed to the wide range of $R_{\mathrm{Fe} / \mathrm{O} 2}$ (Fig.

$1293 b)$. High $R_{\mathrm{Fe} / \mathrm{O} 2}$ efficiencies were observed at the $\mathrm{SAZ}$ site $(148-421 \mu \mathrm{mol} / \mathrm{mol})$ but were one-

130 to two-orders of magnitude lower at both Mediterranean sites. These trends in $R_{\mathrm{Fe} / \mathrm{O} 2}$ are

131 consistent with vertical DFe stocks increasing with depth at SAZ, and in contrast decreasing

132 at the Mediterranean sites (Supplementary-Fig. 3). Similarly, replenishment rates of P and C

133 were highest at SAZ (Supplementary-Table 2). Although the present study offers a snapshot

134 of the annual cycle of mesopelagic remineralization, our observations are consistent with

135 high-latitude studies characterized as sites with relatively labile particles prone to microbially-

136 mediated remineralization ${ }^{28,29}$.

138 Despite the complex transformations that characterize the internal cycle of $\mathrm{Fe}$, a strong

139 inverse relationship is observed between $R_{\mathrm{Fe} / \mathrm{O} 2}$ and the composition of the PFe flux estimated

140 from the particulate $\mathrm{Fe} / \mathrm{C}$ ratio (Fig. 3b). Critically, this inverse relationship reveals that $R_{\mathrm{Fe} / \mathrm{O} 2}$

141 is not determined by the magnitude of the PFe flux but rather by its particle composition

142 (Supplementary-Fig. 2g-h). Furthermore, this negative relationship strongly suggests that

143 biogenic PFe is efficiently regenerated while the dissolution of lithogenic PFe (predominant

144 at the Mediterranean sites; Fig. 2) takes place at much lower rates, corroborating 1D model

145 simulations showing that biogenic and lithogenic PFe fluxes exhibit distinctly different 146 vertical attenuation ${ }^{9}$.

148 Drivers of mesopelagic iron remineralization - To develop a better understanding of the

149 drivers of mesopelagic iron biogeochemistry, $R_{\mathrm{Fe} / \mathrm{O} 2}$ was converted into a $\mathrm{Fe} / \mathrm{C}$ regeneration 150 ratio $\left(R_{\mathrm{Fe} / \mathrm{C}} ;\right.$ Methods) and compared with the $\mathrm{Fe} / \mathrm{C}$ and biogenic $\mathrm{Fe} / \mathrm{C}\left(\mathrm{Fe}_{\mathrm{bio}} / \mathrm{C}\right)$ 
151 stoichiometries of the intercepted particles (Fig. 3c). A positive linear relationship (i.e.,

152 similar biogenic flux and regenerative stoichiometries) should be observed if bacterial 153 solubilization exerts a first-order control on DFe resupply. Here, the absence of such a

154 relationship, along with systematically lower $\mathrm{DFe}$ replenishment rates relative to $\mathrm{P}$ and $\mathrm{C}$

155 (Supplementary-Table 2), confirm that DFe resupply results from a combination of biotic and 156 abiotic transformations of sinking $\mathrm{PFe}^{15,17}$. As highlighted in Fig. 3c, dissolution of lithogenic

157 Fe (i.e., DFe release without $\mathrm{O}_{2}$ consumption) increases $R_{\mathrm{Fe} / \mathrm{O} 2}$ and hence $R_{\mathrm{Fe} / \mathrm{C} \text {, whereas } \mathrm{Fe}}$

158 scavenging (i.e., DFe removal without $\mathrm{O}_{2}$ consumption) has the opposite effect. As expected

159 for areas dominated by biogenic $\mathrm{PFe}$ such as the subantarctic, bacterial solubilization 160 explained most of the $R_{\mathrm{Fe} / \mathrm{C}}$ relative to that of scavenging (Fig. 3c). The relatively large excess

161 in post-incubation Fe-binding ligands ( $\mathrm{L}^{*}$ ) observed at SAZ (Fig. 4), driven by bacterial 162 degradation of biogenic-dominated sinking particles ${ }^{9,16}$, is consistent with these low 163 scavenging rates pointing to complex interplay between processes associated with biogenic 164 and lithogenic PFe.

165

166 In contrast, a pronounced mismatch was observed between $R_{\mathrm{Fe} / \mathrm{C}}$ and the biogenic flux 167 stoichiometry at ALG at the deeper depth (195 m) and both depths at ION (Fig. 3c). Although 168 this trend results from the dominance of particle scavenging over solubilization/dissolution 169 (Fig. 4), the increase of this mismatch with depth may be explained by increasing scavenging $170 \mathrm{and} /$ or decreasing solubilization/dissolution. Saharan dust-derived Fe dissolution rates are 171 reported to remain constant for several days in lab-studies ${ }^{30}$, arguing for a relatively constant 172 dissolution rate over this $115-195 \mathrm{~m}$ stratum that particles will sink through on this 173 timescale ${ }^{7,9}$. Although changes in the bacterial solubilization rate of PFe, over this depth 174 range, cannot be directly assessed, the increasing proportion of $\mathrm{C}$ respired with depth 175 (Supplementary-Table 2) is not consistent with decreased bacterial solubilization rate of PFe 
176 (by assuming constant or increasing biogenic $\mathrm{Fe} / \mathrm{C}$ ratio ${ }^{15}$ ). Thus, increased scavenging (Fig.

1774 ), is the most likely mechanism to account for the trend in $R_{\mathrm{Fe} / \mathrm{C}}$ with depth.

178

179 Measurements of size and concentration of particles collected at the Mediterranean sites

180 revealed decreasing cumulative particle volume concentrations with depth (Supplementary-

181 Table 4), excluding these two parameters as possible drivers of increased scavenging rate.

182 Therefore, the increase with depth in the relative proportion of lithogenic material being

183 exported (Supplementary-Fig. 2b and f), and the resulting decrease in the release of Fe-

184 binding ligands (Supplementary-Table 3), are most likely jointly responsible for this shift

185 within the upper mesopelagic (115-195 m; ALG/ION) stratum in the balance between

186 remineralization of biogenic PFe (DFe and ligand release), dissolution of lithogenic PFe (DFe

187 release) and scavenging processes. These findings demonstrate the confounding role played

188 by dust-derived lithogenic particles, conventionally viewed as a major pelagic DFe source ${ }^{2,5}$,

189 but shown here in the upper $100-200 \mathrm{~m}$ stratum to act primarily as a scavenging-modulated

190 sink for DFe, and as a ballasting agent ${ }^{25,31,32}$, each influencing where in the water column DFe

191 is replenished.

192

193 Vertical resetting of mesopelagic biogeochemical conditions - Figure 4 summarises how

194 the interplay of biogenic and lithogenic processes establish iron biogeochemical conditions at

195 each site, and importantly reset conditions with depth. Biogenic PFe is the main source of

196 DFe replenishment via bacterial solubilization, and this is also the case for the concurrent

197 release of iron-binding ligands. By combining the observations from TM-RESPIRE with

198 dissolution rate and scavenging ratios derived from prior dust-addition studies ${ }^{18,30}$, it is

199 evident that lithogenic PFe contributes $\sim 10$ times more to Fe scavenging relative to Fe

200 dissolution in the upper mesopelagic (Fig. 4) supporting our observations in Fig. 3c. It is 
important to note that high scavenging rates were reported even when $\mathrm{L}^{*}$ was (slightly)

202 positive (Fig. 3c and 4). It is probable that the higher the value of $\mathrm{L}^{*}$ the less likelihood of 203 pronounced scavenging, however, this trend, of scavenging when $\mathrm{L}^{*}$ is positive, points to an

204 unknown or unexplored mechanism (e.g., sorption of complexed Fe, colloidal aggregation).

205 These contrasting biogenic and lithogenic roles point to the importance of the composition of 206 the PFe flux in setting the Fe remineralization length-scale, with high PFe attenuation at the 207 biogenic end-member site, and in contrast an increase in PFe sinking flux at the lithogenic 208 end-member site.

210 Conceptually, depth-dependant changes in the relative proportion of biogenic vs. lithogenic 211 PFe, driven by their different attenuation length-scales, result in an ongoing resetting of the 212 biogeochemical conditions (e.g., L*, ballasting via changes to the specific gravity of the 213 particle) while particles are settling in the water column (Fig. 4). The vertical trend observed 214 at the ALG site - characterized by intermediate surface characteristics relative to the two 215 other sites (Fig. 1c) - illustrates this dynamic situation. At $115 \mathrm{~m}$ depth, bacterial degradation 216 of heterogenous (i.e., biogenic/lithogenic) particles resulted in a relatively high post217 incubation L* (Fig. 4) and a low scavenging rate (Fig. 3c and 4). However, $80 \mathrm{~m}$ deeper, 218 alteration of the composition of the PFe flux resulted in a decrease in post-incubation L* (Fig. 219 4; Supplementary-Table 3) and a marked increase in the scavenging rate (Fig. 3c and 4). A 220 similar increase in scavenging with depth was observed at the ION site (Fig. 4). The dynamic 221 interplay between biogenically- and lithogenically-modulated mechanisms explain the 222 unexpected high spatial (and by analogy, temporal) and vertical variability in the PFe 223 remineralization reported in this study, but not so far captured in biogeochemical models ${ }^{7}$. 
225 We report a thousand-fold range in the DFe replenishment rate, while only modest changes

226 in $\mathrm{P}$ and $\mathrm{C}$ remineralization rates occurred at all sites (Supplementary-Table 2). At the SAZ,

227 the decoupling between $\mathrm{Fe}$ and $\mathrm{C}$ remineralization was relatively low and comparable to that

228 reported for sinking diatoms in subtropical waters ${ }^{15}$. In contrast, a pronounced decoupling

229 between Fe and both $\mathrm{C}$ and P remineralization was observed at ALG and ION. Critically, the

230 lithogenic component of the sinking flux, by having virtually no influence on $\mathrm{C}$ and $\mathrm{P}$

231 remineralization, amplifies the decoupling between the $\mathrm{Fe}$ and both the $\mathrm{C}$ and $\mathrm{P}$

232 remineralization length-scales. This finding highlights that the multi-faceted effects of particle

233 composition and dynamics on mesopelagic iron recycling needs to be considered in global

234 biogeochemical models, to better explain the spatial variability in the decoupling of nutrient

235 recycling.

236

237 Controls on the global iron distribution - The most straightforward route to examining the

238 broader role of biogenic:lithogenic particle composition on iron distributions was to focus on

239 the links to lithogenic iron, as dust supply is a well-established component of iron

240 biogeochemical models ${ }^{4}$. The modelling simulations exploited the observed $\mathrm{Fe} / \mathrm{O}_{2}$

241 relationship with dust (Fig. 3b-c) to develop a simple first-order parameterization that

242 captures observed links between $\mathrm{Fe} / \mathrm{O}_{2}$ and dust (Fig. 5a). Thus, an additional modulator of $\mathrm{Fe}$

243 remineralization, based on the atmospherically-derived lithogenic particle concentration, was

244 added to the PISCES model parameterization, which enabled the sensitivity of iron

245 biogeochemistry to the impact of lithogenic particles on mesopelagic DFe cycling to be 246 addressed (Methods).

248 This simulation was employed to assess the wider implications of the multi-faceted roles of 249 lithogenic Fe on ocean iron cycling. Projections of the upper mesopelagic (100-250 m) DFe 
inventory, in this amended simulation, decreased by $23.7 \%$ relative to the control run (Fig.

$2515 \mathrm{~b})$ and as expected, this trend was especially marked in areas influenced by high dust 252 deposition (i.e., North Atlantic, North Pacific, and Indian Oceans). In parallel, the DFe 253 inventory between $1000-1250 \mathrm{~m}$ depth increased by $6.4 \%$ across the global ocean (Fig. 5b).

254 Ultimately, the effect of lithogenic particles on PFe remineralization is to deepen the vertical 255 profile of DFe and therefore drive the replenishment of DFe deeper in the water column (Fig. 256 5c). This significant redistribution of DFe over the upper $1000 \mathrm{~m}$ has important ramifications 257 when considering that this depth stratum is heavily influenced by mode and intermediate 258 waters lateral transport ${ }^{33}$, which can then alter DFe supply to different ocean regions and the 259 associated primary production (Supplementary-Fig. 4b). Therefore, the vertical redistribution 260 of iron in regions dominated by settling lithogenic particles may be pronounced when changes 261 in dust delivery to the ocean ${ }^{34}$ may be accompanied by altered ocean circulation in the coming 262 decades $^{5}$.

264 Our findings suggest that predicted changes in dust inputs ${ }^{34}$, by altering the 265 biogenic:lithogenic composition of the sinking particle assemblage, may impact the 266 replenishment of the subsurface DFe inventory and vertical supply of DFe not only in dusty 267 regions, but across the global ocean. This alteration, across many oceanic provinces, of DFe 268 resupply may in return have profound effects on the carbon sequestration efficiency of the 269 biological pump ${ }^{35}$. Our study enhances the wider understanding of the role of dust in altering 270 particle composition which in turn influences the replenishment of the subsurface DFe 271 inventory. This research points to the need for further studies on the internal cycling of trace 272 metals if we are to fully understand how they are returned to surface waters via their 273 biogeochemical cycles. 


\section{References}

1. Moore, C. M. et al. Processes and patterns of oceanic nutrient limitation. Nat. Geosci. 6, 701-710 (2013).

2. Jickells, T. D. et al. Global iron connections between desert dust, ocean biogeochemistry, and climate. Science 308, 67-71 (2005).

3. Guieu, C., et al. Iron from a submarine source impacts the productive layer of the Western Tropical South Pacific (WTSP). Sci. Rep. 8, 9075 (2018).

4. Tagliabue, A. et al. How well do global ocean biogeochemistry models simulate dissolved iron distributions? Glob. Biogeochem. Cycles 30, 149-174 (2016).

5. Tagliabue, A. et al. The integral role of iron in ocean biogeochemistry. Nature 543, 51-59 (2017).

6. GEOTRACES Planning Group. GEOTRACES Science Plan. Baltimore, Maryland: Scientific Committee on Oceanic Research (2006).

7. Boyd, P. W., Ellwood, M. J., Tagliabue, A., \& Twining, B. S. Biotic and abiotic retention, recycling and remineralization of metals in the ocean. Nat. Geosci. 10, 167-173 (2017).

8. Tagliabue, A. et al. Surface-water iron supplies in the Southern Ocean sustained by deep winter mixing. Nat. Geosci. 7, 314-320 (2014).

9. Boyd, P. W., Ibisanmi, E., Sander, S. G., Hunter, K. A., \& Jackson, G. A. Remineralization of upper ocean particles: Implications for iron biogeochemistry. Limnol. Oceanogr. 55, 1271-1288 (2010).

10. Ye, Y., Wagener, T., Völker, C., Guieu, C., \& Wolf-Gladrow, D. A.. Dust deposition: iron source or sink? A case study. Biogeosciences 8, 2107-2124 (2011).

11. Völker, C., \& Tagliabue, A. Modeling organic iron-binding ligands in a three-dimensional biogeochemical ocean model. Mar. Chem. 173, 67-77 (2015). 
12. Frew, R. D. et al. Particulate iron dynamics during FeCycle in subantarctic waters

300 southeast of New Zealand. Glob. Biogeochem. Cycles 20, GB1S93 (2006).

301 13. Lamborg, C. H., Buesseler, K. O., \& Lam, P. J. Sinking fluxes of minor and trace

302 elements in the North Pacific Ocean measured during the VERTIGO program. Deep Sea

$303 \quad$ Res. Part II 55, 1564-1577 (2008).

304 14. Ellwood, M. J. et al. Pelagic iron cycling during the subtropical spring bloom, east of $305 \quad$ New Zealand. Mar. Chem. 160, 18-33 (2014).

306 15. Twining, B. S. et al. Differential remineralization of major and trace elements in sinking 307 diatoms. Limnol. Oceanogr. 59, 689-704 (2014).

308 16. Velasquez, I. B. et al. Ferrioxamine siderophores detected amongst iron binding ligands 309 produced during the remineralization of marine particles. Front. Mar. Sci. 3, 172 (2016).

310 17. Boyd, P. W., \& Ellwood, M. J. The biogeochemical cycle of iron in the ocean. Nat. 311 Geosci. 3, 675-682 (2010).

312 18. Wagener, T., Guieu, C., \& Leblond, N. Effects of dust deposition on iron cycle in the 313 surface Mediterranean Sea: results from a mesocosm seeding experiment. Biogeosciences $314 \quad 7,3769-3781(2010)$.

315 19. Bressac, M., \& Guieu, C. Post-depositional processes: What really happens to new 316 atmospheric iron in the ocean's surface? Glob. Biogeochem. Cycles 27, 859-870 (2013).

317 20. Wuttig, K. et al. Impacts of dust deposition on dissolved trace metal concentrations (Mn, $318 \quad \mathrm{Al}$ and Fe) during a mesocosm experiment. Biogeosciences 10, 2583-2600 (2013).

319 21. Burd, A. B. et al. Assessing the apparent imbalance between geochemical and 320 biochemical indicators of meso-and bathypelagic biological activity: What the @\$ $\$$ ! is 321 wrong with present calculations of carbon budgets? Deep Sea Res. Part II 57, 1557-1571 322 (2010). 
22. Boyd, P. W., McDonnell, A., Valdez, J., Lefèvre, D., \& Gall, M. P. RESPIRE: An in situ particle interceptor to conduct particle remineralization and microbial dynamics studies in the oceans' Twilight Zone. Limnol. Oceanogr. Methods 13, 494-508 (2015).

23. Albani, S. et al. Improved dust representation in the Community Atmosphere Model. $J$. Adv. Model Earth Sy. 6, 541-570 (2014).

24. Sedwick, P. N., et al. Limitation of algal growth by iron deficiency in the Australian Subantarctic region. Geophys. Res. Lett. 26, 2865-2868 (1999).

25. Bressac, M. et al. Quantification of the lithogenic carbon pump following a simulated dust-deposition event in large mesocosms. Biogeosciences 11, 1007-1020 (2014).

26. Ternon, E. et al. The impact of Saharan dust on the particulate export in the water column of the North Western Mediterranean Sea. Biogeosciences 7, 809-826 (2010).

27. Trull, T. W., Bray, S. G., Manganini, S. J., Honjo, S., \& Francois, R. Moored sediment trap measurements of carbon export in the Subantarctic and Polar Frontal Zones of the Southern Ocean, south of Australia. J. Geophys. Res. 106, 31489-31509 (2001).

28. Francois, R., Honjo, S., Krishfield, R., \& Manganini, S. Factors controlling the flux of organic carbon to the bathypelagic zone of the ocean. Glob. Biogeochem. Cycles 16, 34-1 (2002).

29. Henson, S. A., Sanders, R., \& Madsen, E. Global patterns in efficiency of particulate organic carbon export and transfer to the deep ocean. Glob. Biogeochem. Cycles 26, GB1028 (2012).

30. Wagener, T., Pulido-Villena, E., \& Guieu, C. Dust iron dissolution in seawater: Results from a one-year time-series in the Mediterranean Sea. Geophys. Res. Lett. 35, L16601 (2008). 
31. Louis, J., Pedrotti, M. L., Gazeau, F., \& Guieu, C. Experimental evidence of formation of Transparent Exopolymer Particles (TEP) and POC export provoked by dust addition under current and high $\mathrm{pCO}_{2}$ conditions. PloS one 12, e0171980 (2017).

32. Pabortsava, K. et al. Carbon sequestration in the deep Atlantic enhanced by Saharan dust. Nat. Geosci. 10, 189 (2017).

33. Hanawa, K. \& Talley, L. D. in Ocean Circulation and Climate. Eds Siedler, G. \& Church, J., Academic, San Diego, 373-386 (2001).

34. Mahowald, N. M., \& Luo, C. A less dusty future?. Geophys. Res. Lett. 30, 1903 (2003).

35. Blain, S. et al. Effect of natural iron fertilization on carbon sequestration in the Southern Ocean. Nature 446, 1070-1074 (2007).

Corresponding author - Correspondence and requests for materials should be addressed to M.B. (matthieu.bressac@utas.edu.au).

Acknowledgements - We thank the captains and crew of the $R V$ Investigator and $R V$ Pourquoi Pas?, the CSIRO and DT INSU teams for the design and preparation of the mooring line, C. Young and P. Waller for building the TM-RESPIRE. The CSIRO Hydrochemistry team, S. Albani, N. Bhairy, E. Cavan, X. Chan, G. De Liège, J. Derrick, K. Desboeufs, F. D’Ortenzio, A. Dufour, M. Garel, J. Guittonneau, N. Haentjens, S. Helias Nunige, S. Jacquet, P. Jansen, N. Leblond, D. Lefèvre, H. Planquette, C. Ridame, G. Rougier, V. Tallendier, C. Tamburini, A. Tovar-Sanchez and T. Trull are thanked for their help at sea and/or samples analysis. This project was funded by a Marie Sklodowska-Curie Postdoctoral European Fellowship awarded to M.B (European Union Seventh Framework Programme ([FP7/2007-2013]) under grant agreement no. [PIOF-GA-2012-626734] (IRON-IC project)). This study is a contribution to the PEACETIME project (http://peacetime-project.org), a joint 
initiative of the MERMEX and ChArMEx components supported by CNRS-INSU,

372 IFREMER, CEA, and Météo-France as part of the programme MISTRALS coordinated by

373 INSU. This study was also partly funded by the Australian Research Council by a Laureate

374 awarded to P.W.B (FL160100131), and Discovery project awarded to M.J.E and P.W.B.

375 (DP170102108).

376

377 Author contributions - M.B. designed and carried out the study, analysed the data, and 378 wrote the manuscript. C.G. and P.W.B. helped in the design of the study and co-led the 379 cruises. P.W.B. worked on the different versions of the manuscript. M.J.E., T.W., and 380 E.C.L.C. helped in the different instrument deployments and sampling. M.J.E., and T.W. 381 helped in the analysis of samples. A.T. provided and helped interpret the PISCES model 382 output. H.W. and G.S. analyzed the ligand samples. All authors commented on and 383 contributed to the improvement of the manuscript.

385 Competing interests - The authors declare no competing interests.

Figure 1. In situ particle remineralization measurements at contrasting biogeochemical

388 sites. a, Conceptual alteration of particles within the (TM-)RESPIRE. Sinking particles are 389 intercepted for $\sim 36 \mathrm{~h}$ and regularly transferred into the inner chamber. Next, particles are 390 immediately incubated for $>24 \mathrm{~h}$ at in situ pressure and temperature during which bacterial 391 solubilization (i.e., diminished green particles) releases elements. See Methods for chemical 392 assays, and corrections applied to obtain pre-incubation particulate concentrations. b, Typical 393 oxygen optode time-series measured within RESPIRE. Bacterially-mediated remineralization 394 is derived from $\Delta \mathrm{O}_{2 \max }$ and $\Delta \mathrm{t}$ (i.e., the time-period where the slope of the linear regression is 395 maximum). c, Weekly chlorophyll climatology from Modis-Aqua (green; 2003-2017; $1^{\circ} \times 1^{\circ}$ 
resolution) and monthly climatology of simulated dust deposition (brown; $0.9^{\circ} \times 1.25^{\circ}$

397 resolution) ${ }^{23}$ in the subantarctic (SAZ: upper-panel), and Mediterranean Sea (ALG: middle;

398 ION: lower-panel). Grey vertical bars are (TM-)RESPIRE sampling periods.

Figure 2. Summary of downward particle fluxes and composition from (TM-)RESPIRE

(mmol $\mathrm{m}^{-2} \mathrm{~d}^{-1}$; averaged (TM-)RESPIRE fluxes) at each depth (left-hand downward arrow,

corresponding to the centre of each circle). PFe fluxes $\left(\mu \mathrm{mol} \mathrm{m} \mathrm{m}^{-2} \mathrm{~d}^{-1}\right)$ are represented by

404 coloured circle rims, and the partitioning of the PFe flux by the proportion of grey

405 (lithogenic) and white (biogenic) within each circle (Methods). All fluxes were corrected for bacterial remineralization during the incubation (Methods). The circle size represents the flux magnitude (Supplementary-Table 1) and are enlarged 10-fold (inside the dashed rectangle) at

408 the low-flux SAZ site. At SAZ, fluxes are the mean of two successive deployments (same 409 depth).

Figure 3. Bacterial particle remineralization and iron regeneration efficiency at SAZ (green), ALG (red) and ION (blue). a, Remineralization versus POC concentrations

413 (corrected for remineralization during the incubation) measured within RESPIRE at $115 \mathrm{~m}$ 414 (triangles), $160 \mathrm{~m}$ (circles), and $195 \mathrm{~m}$ (diamonds). The best-fit of the linear model is plotted. 415 b, Regeneration efficiencies $\left(R_{\mathrm{Fe} / \mathrm{O} 2}\right)$ versus the $\mathrm{Fe} / \mathrm{C}$ molar ratios of intercepted particles (a 416 proxy for PFe flux composition, higher ratios have more $\mathrm{PFe}_{\text {litho; }}$, Methods). The best-fit of the 417 power law model is presented. c, Fe/C regeneration ratios $\left(R_{\mathrm{Fe} / \mathrm{C}}\right)$, obtained from $R_{\mathrm{Fe} / \mathrm{O} 2}$ and a $418 \mathrm{C}: \mathrm{O}_{2}$ conversion factor (Methods), versus the bulk (open symbols) and biogenic $\left(\mathrm{Fe}_{\mathrm{bio}} / \mathrm{C}\right.$; 419 Methods; closed symbols) Fe/C molar ratios. To aid interpretation, Fe-specific processes 420 (vertical arrows) in relation to $R_{\mathrm{Fe} / \mathrm{C}}$ and $\mathrm{Fe}_{\mathrm{bio}} / \mathrm{C}$ are displayed. The grey triangle illustrates the 
421 increasing proportion of lithogenic PFe across sites and with depth. Error bars were derived

422 using uncertainty-propagation laws (Methods). Fluxes were expressed as concentrations to 423 permit cross-comparison between sites (different collection/incubation times employed).

Figure 4. Synthesis of key processes that together set the PFe remineralization lengthscale expressed as a function of the relative proportion of sinking biogenic:lithogenic

PFe. Sites and depths are assigned into each of three idealized categories: biogenic-dominated (SAZ), heterogeneous (biogenic/lithogenic; ALG $115 \mathrm{~m}$ ), and lithogenic-dominated (ALG $195 \mathrm{~m}$, ION 115-195 m) PFe fluxes. Note, how intercepted sinking particles at ALG shift categories with depth. For PFe attenuation, + and - denote the magnitude of the decrease or increase in the flux with depth, respectively. Note, the dynamic nature of concurrent ligand release and scavenging as particles settle, means that $\mathrm{L}^{*}>0$ may not impede scavenging (see Fig. 3c). Nevertheless, the higher the value of $\mathrm{L}^{*}$ the less likelihood of pronounced 434 scavenging.

Figure 5. Results of model simulations using lithogenic particle-dependent modulation of iron remineralization. a, Relationship between $R_{\mathrm{Fe} / \mathrm{O} 2}$ and lithogenic $\mathrm{PFe}$ concentrations in offshore regions $\left(>3000 \mathrm{~m}\right.$ depth; $\left.30^{\circ} \mathrm{S}-30^{\circ} \mathrm{N}\right)$ employing different lithogenic particledependent modulators of iron remineralization ( $k d$; Methods). b, Change in DFe inventory vertically integrated over 100-250 m (upper-panel) and 1000-1250 m (lower-panel) depth

441 strata relative to the control run. This simulation is based on a 500-year simulation employing

442 a kd of $0.1 \mu \mathrm{g} \mathrm{m}^{-3}$ (i.e., which reproduced the inverse relationship observed between $R_{\mathrm{Fe} / \mathrm{O} 2}$ 443 and the lithogenic PFe concentration in panel a). c, Alteration of the global mean vertical DFe 444 profile from a simulation employing a $\mathrm{kd}$ of $0.1 \mu \mathrm{g} \mathrm{m}^{-3}$ relative to the control run. 
METHODS

447 Site selection - Datasets were acquired during two GEOTRACES process studies, in the Subantarctic Zone (SAZ) southwest of Tasmania, aboard the RV Investigator (March 2017;

449 SOTS project), and in the central (Ionian Sea, ION) and western (Algerian Basin, ALG) Mediterranean Sea aboard the RV Pourquoi Pas? (May/June 2017; Peacetime project). Sites were selected for their contrasting magnitude and composition of the downward particle flux.

452 In particular, $\sim 30$-fold higher lithogenic fluxes have been reported at $\sim 1000 \mathrm{~m}$ depth at ALG $\left(12.7 \mathrm{~g} \mathrm{~m}^{-2} \mathrm{yr}^{-1}\right)^{36}$ and ION $\left(13.9 \mathrm{~g} \mathrm{~m}^{-2} \mathrm{yr}^{-1}\right)^{37}$, relative to SAZ $\left(0.4 \mathrm{~g} \mathrm{~m}^{-2} \mathrm{yr}^{-1}\right)^{27}$. In contrast, 454 POC fluxes at $\sim 1000 \mathrm{~m}$ depth are relatively similar at SAZ (1.1-1.4 $\left.\mathrm{g} \mathrm{m}^{-2} \mathrm{yr}^{-1}\right)^{38}$, ALG (1.4$\left.1.7 \mathrm{~g} \mathrm{~m}^{-2} \mathrm{yr}^{-1}\right)^{36}$, and ION $\left(0.7-0.9 \mathrm{~g} \mathrm{~m}^{-2} \mathrm{yr}^{-1}\right)^{37}$.

The SAZ represents $>50 \%$ of the areal extent of the ice-free Southern Ocean. This HNLC area has both low silicate and DFe concentrations year round ${ }^{24}$ along with moderate phytoplankton biomass $^{39}$. The low dust flux to this area originates primarily from Australia, with the highest fluxes between October and $\operatorname{March}^{40}$. POC (0.91-1.23 $\left.\mathrm{mmol} \mathrm{m}^{-2} \mathrm{~d}^{-1}\right)$ and PFe $460\left(0.48-0.67 \mu \mathrm{mol} \mathrm{m}{ }^{-2} \mathrm{~d}^{-1}\right)$ fluxes measured in this study compared well with POC $(3.34 \pm 1.81$ $\left.461 \mathrm{mmol} \mathrm{m} \mathrm{m}^{-1}\right)^{41}$ and PFe $\left(0.17 \pm 0.09 \mu \mathrm{mol} \mathrm{m}^{-2} \mathrm{~d}^{-1}\right)^{42}$ fluxes measured at the same site and 462 depth, but in January/February.

463 The Mediterranean Sea has a west-to-east gradient of increasing oligotrophy, with a

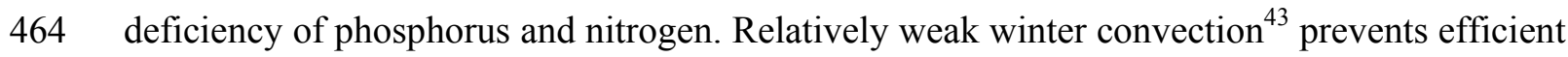
465 uplift of nutrients to the surface waters. Deposition of Saharan desert dust, characterized by 466 strong variability and dominated by extreme events ${ }^{44}$, constitutes the main source of new 467 nutrients. ION is an ultra-oligotrophic area, while the ALG is one of the most productive 468 areas in the Mediterranean $\mathrm{Sea}^{45}$. At ALG/ION, POC fluxes measured at $195 \mathrm{~m}$ depth (1.14$\left.4691.67 \mathrm{mmol} \mathrm{m} \mathrm{d}^{-2}\right)$ are consistent with previous measurements $\left(0.4-3.0 \mathrm{mmol} \mathrm{m} \mathrm{m}^{-2} \mathrm{~d}^{-1}, 1^{\mathrm{st}} / 3^{\text {rd }}\right.$ 470 quartiles $)^{46}$, but $\sim 4$-fold higher than fluxes simultaneously measured at $250 \mathrm{~m}$ depth with a 
471 PPS5 sediment trap (0.32-0.37 $\mathrm{mmol} \mathrm{m}^{-2} \mathrm{~d}^{-1}$; N. Leblond, pers. comm.). Similarly, 2-fold

472 higher PFe fluxes were collected at $195 \mathrm{~m}$ depth with the TM-RESPIRE (13.4-16.1 $\mu \mathrm{mol} \mathrm{m}{ }^{-2}$

$473 \mathrm{~d}^{-1}$ ) compared to PFe fluxes at $250 \mathrm{~m}$ depth (PPS5; 4.5-8.5 $\mu \mathrm{mol} \mathrm{m}^{-2} \mathrm{~d}^{-1} ; \mathrm{N}$. Leblond, pers. 474 comm.).

476 (TM-)RESPIRE - The conceptual view, functioning and potential artefacts of the RESPIRE 477 particle interceptor are detailed in ref. $^{22}$. TM-RESPIRE, a trace metal-clean version of 478 RESPIRE, was developed to quantify PFe remineralization rates. TM-RESPIRE is 479 constructed from polycarbonate (PC) except for the PVC indented rotating sphere (IRS), and 480 has identical dimensions to RESPIRE (Supplementary-Fig. 1). The IRS excludes 481 mesozooplankton from the incubation chamber, and delivers particles every $\sim 10$ min into this 482 chamber. When the IRS is not rotating, the chamber beneath it is completely closed, avoiding 483 any exchange with the upper part of TM-RESPIRE. Trace metal cleanliness and optode-based 484 oxygen measurements are not reconcilable since plastic material essential for trace elements 485 studies often have high oxygen permeability, and optodes require a metal window. To 486 circumvent these issues, TM-RESPIRE was systematically deployed concurrently with the 487 RESPIRE fitted with an Aanderaa 3830 oxygen optode (resolution $<1 \mu \mathrm{M}$; accuracy $<5$ $488 \mu \mathrm{M})$.

489 Optodes were post-calibrated using the Winkler method, and oxygen time-series were 490 corrected for pressure and salinity (Aanderaa operating manual). A pressure sensor (RBR, 491 Canada) was deployed alongside RESPIRE to determine the deployment depth. The vertical 492 distance between the TM-RESPIRE and RESPIRE (10-20 m; Supplementary-Table 1) was 493 constrained by the ship's dimensions (i.e., distance above the waterline) and the necessity to 494 keep a minimum distance between the two traps to avoid contamination through contact with 495 the vessels' hull or propeller wash during deployment/recovery. 
496 Remineralization rates measured within the RESPIRE were assumed to be comparable in the

497 TM-RESPIRE. This assumption is supported by similar rates obtained at SAZ after two

498 successive deployments several days apart $\left(5.1 \pm 0.2 \mathrm{mmol} \mathrm{O}_{2} \mathrm{~m}^{-3} \mathrm{~d}^{-1}\right.$; Fig. 3a), and by

499 previous replicate RESPIRE measurements exhibiting small variability in the remineralization

500 rates $^{47}$. In the present study, POC fluxes from RESPIRE and TM-RESPIRE (vertically

501 separated by $10-20 \mathrm{~m})$ varied on average by a factor of $1.8 \pm 0.6(\mathrm{n}=6)$. Similar POC flux

502 variabilities were observed at ALG/ION (250 $\mathrm{m}$ depth) and SAZ (150 m depth) across

503 individual 12-24 h samples obtained by conventional sediment traps which varied on average

504 by $1.6 \pm 0.8$ (N. Leblond, pers. comm.) and $3^{(41)}$, respectively. This relatively high variability

505 in successive upper mesopelagic POC flux measurements suggests that the differences

506 observed in the present study is driven largely by inherent variability in the POC flux in this

507 stratum $^{48}$, rather than by the vertical spacing between the RESPIRE and TM-RESPIRE.

509 (TM-)RESPIRE procedure - RESPIRE were cleaned following ref. $^{22}$. Before each voyage,

510 TM-RESPIRE were soaked in 2\% Neutracon (7d), $2 \mathrm{M} \mathrm{HCl}$ (reagent grade; 30d), $1.2 \mathrm{M} \mathrm{HCl}$

511 (TM grade; 7d), and copiously rinsed with Ultrapure water. Before deployment, each TM-

512 RESPIRE was filled overnight with $0.12 \mathrm{M} \mathrm{HCl}$ (TM grade), rinsed with Ultrapure water and

513 pre-conditioned with low-Fe filtered seawater to remove all trace of acid. Several hours

514 before deployment, RESPIRE and TM-RESPIRE were filled with filtered seawater collected

515 at the deployment depth. Clean polyethylene (PE) bags covering the traps were removed just

516 prior to deployment. Upon recovery, RESPIRE and TM-RESPIRE were immediately covered

517 with PE bags. TM-RESPIRE's were transferred into a class-100 clean laboratory. Seawater

518 above the IRS was siphoned off using clean Teflon PFA tubing, and the incubation chamber

519 was sampled via a Teflon PFA stopcock valve. The absence of mesozooplankton in the

520 chamber was confirmed by visual inspection. Samples were split into equal fractions and 
521 subsamples for DFe, Fe-binding ligands, and nutrients were filtered through acid-cleaned 0.2-

$522 \mu \mathrm{m}$ PC membranes. DFe samples were stored in low density PE (LDPE) bottles and acidified

523 to $\mathrm{pH} 1.8$ (quartz-distilled $\mathrm{HCl}$ ). Fe-binding ligand samples were transferred to high density

524 PE bottles (cleaned following GEOTRACES protocols,

525 http://www.geotraces.org/science/science-highlight/intercalibration/222-sampling-and-

526 sample-handling-protocols-for-geotraces-cruises), double-bagged and stored at $-20^{\circ} \mathrm{C} .0 .2-\mu \mathrm{m}$

527 PC membranes were dried under a laminar flow hood and used for particulate trace element

528 analysis. Subsamples for POC were obtained by filtration onto pre-combusted 13-mm QMA

529 or GF/F filters. RESPIRE was sampled for POC and nutrients. All steps were performed

530 within 2-3 hours of recovery of (TM-)RESPIRE.

531 TM-RESPIRE procedural blank measurements were performed onboard during voyages.

532 Blanks comprised incubating $<0.2-\mu \mathrm{m}$ seawater from $150 \mathrm{~m}$ depth within the TM-RESPIRE.

533 After $72 \mathrm{~h}$, the blank samples were subjected to identical processing protocols (i.e.,

534 subsampling, filtration) as for deployments. The average DFe blank ( $\mathrm{DFe}_{\text {blank }} ; 0.38 \pm 0.03$

$535 \mathrm{nM}$ ) was used to correct DFe release (see Calculation of metrics). However, we acknowledge

536 that deployment and recovery are two steps with high risk of contamination. Concentrations

537 in trace elements other than Fe (such as $\mathrm{Zn}$ ) measured within the TM-RESPIRE were used to

538 assess possible contamination (not necessarily conspicuous with DFe) that could have

539 occurred during deployment/recovery. This approach allowed us to reject one contaminated

540 deployment (Subantarctic voyage, April 2016).

541

542 Water column sampling - Samples were collected using a Titanium Rosette mounted with

543 Teflon-coated 12 L Niskin (SAZ) or Go-Flo bottles (ALG/ION) deployed on a Kevlar cable.

544 After recovery, bottles were transferred inside a class-100 clean laboratory container.

545 Seawater samples were directly filtered from the bottles through acid-cleaned $0.2-\mu \mathrm{m}$ capsule 
546 filters (Sartorius Sartobran-P-capsule 0.45/0.2- $\mu \mathrm{m}$ ). DFe samples were stored in LDPE bottles

547 and acidified to $\mathrm{pH} 1.8$ (quartz-distilled $\mathrm{HCl}$ ), while nutrient samples were analyzed at sea.

548 Suspended particulate trace elements were sampled using in situ pumps (McLane; acid-

549 cleaned 1- $\mu \mathrm{m}$ PC membranes) at SAZ and pressurized Go-Flo bottles at ALG/ION (acid-

550 cleaned $25-\mathrm{mm}$ diameter Supor $0.45-\mu \mathrm{m}$ polyethersulfone filters; $4.8 \mathrm{~L}$ on average) following

551 GEOTRACES recommendations.

552

553 Analytical methods - DFe concentrations were measured by flow injection with online 554 preconcentration and chemiluminescence detection ${ }^{3,49}$. An internal acidified seawater 555 standard was measured daily to control the stability of the analysis. During the analysis of

556 TM-RESPIRE and water-column samples, the detection limit was $15 \mathrm{pM}$ and the accuracy of 557 the method was controlled by analyzing the SAFe $\mathrm{S}(0.086 \pm 0.010 \mathrm{nmol} / \mathrm{kg}(\mathrm{n}=3)$; 558 consensus value $0.093 \pm 0.008 \mathrm{nmol} / \mathrm{kg}), \mathrm{SAFe}$ D1 $(0.64 \pm 0.13 \mathrm{nmol} / \mathrm{kg}(\mathrm{n}=19) ;$ consensus 559 value $0.67 \pm 0.04 \mathrm{nmol} / \mathrm{kg}), \mathrm{GD}(1.04 \pm 0.10 \mathrm{nmol} / \mathrm{kg}(\mathrm{n}=10) ;$ consensus value $1.00 \pm 0.10$ $560 \mathrm{nmol} / \mathrm{kg})$, and GSC $(1.37 \pm 0.16 \mathrm{nmol} / \mathrm{kg}(\mathrm{n}=4)$; consensus value not available $)$ seawater 561 standards.

562 Dissolved nutrients were analysed onboard with a segmented flow analyser (AAIII HR Seal 563 Analytical; detection limits were $0.02 \mu \mathrm{M}$ for $\mathrm{P}, 0.05 \mu \mathrm{M}$ for $\mathrm{N}$, and $0.08 \mu \mathrm{M}$ for $\mathrm{Si})^{50,51}$.

564 Iron organic speciation measurements were performed using CLE-CSV with 2-(2565 Thiazolylazo)-p-cresol (TAC) as the competing ligand ${ }^{52}$. Reagent blanks for Fe were 566 undetectable and the detection limit for ligand concentrations was calculated as 3 times the 567 standard deviation of the concentrations (ranging from 0.09-0.99 $\mathrm{nM}$ and always lower than 568 the concentration).

569 Particulate trace element samples were digested $\left(10 \% \mathrm{HF} / 50 \% \mathrm{HNO}_{3}(\mathrm{v} / \mathrm{v})\right)$ following the 570 protocol described in the "GEOTRACES Cookbook" and ref. ${ }^{53}$. Procedural blanks consisted 
571 of unused acid-cleaned filters. Analyses were performed on a high resolution ICP-MS

572 (Element XR, Thermo-Fisher Scientific). The accuracy of the measurements was established 573 using a range of Certified Reference Materials, including MESS-4. The recoveries in these 574 reference materials were $80-130 \%$ for iron.

575 POC samples were acidified overnight with $2 \mathrm{M} \mathrm{HCl}$ to remove inorganic $\mathrm{C}$, and then dried at $57660^{\circ} \mathrm{C}$ for $2 \mathrm{~d}$. Samples were analyzed on a CHN analyser (Thermo Finnigan EA 1112 Series 577 Flash Elemental Analyser).

579 Calculations of metrics - Mesozooplankton, free-living and particle-attached heterotrophic 580 bacteria drive mesopelagic remineralization ${ }^{54}$. By excluding mesozooplankton (using the IRS) 581 and boosting particle-attached bacterial abundances relative to free-living bacteria (through 582 particle interception), the measured remineralization rates were dominated by the particle583 attached microbial assemblage ${ }^{22}$.

584 Particle remineralization was calculated as follows: the pre-incubation $\mathrm{O}_{2}$ concentration 585 (Fig. 1b) was subtracted from each data-point obtained during the incubation, and the sign 586 reversed. The slope of the linear regression between this remineralization signature and the 587 time elapsed corresponds to the particle remineralization rate. Note that the decrease in $\mathrm{O}_{2}$ 588 was not systematically linear, and a plateau can be attained toward the end of the incubation 589 (Fig. 1b). The explanation for this trend remains unclear, but may be related to particle 590 containment, a shift in the microbial community ${ }^{55}$, and/or altered organic matter lability ${ }^{22}$.

591 When such a plateau was evident, remineralization was calculated over the time period where 592 the decrease in $\mathrm{O}_{2}$ was maximum (Fig. 1b). Since remineralization rates were assumed to be 593 comparable within the RESPIRE and TM-RESPIRE, the error in remineralization rates was 594 calculated by propagating the uncertainty from the slope of the linear regression and the 595 relative standard deviation of the POC fluxes collected by the RESPIRE/TM-RESPIRE. The 
error in $\Delta \mathrm{O}_{2}$ (see below) was calculated in the same way.

597 The iron regeneration efficiency $\left(R_{\mathrm{Fe} / \mathrm{O} 2} ; \mu \mathrm{mol} / \mathrm{mol}\right.$; Fig. $\left.3 \mathrm{~b}\right)$ was calculated as: $R_{\mathrm{Fe} / \mathrm{O} 2}=$ $598 \Delta \mathrm{DFe} / \Delta \mathrm{O}_{2}$, where $\Delta \mathrm{DFe}=\mathrm{DFe}_{\text {post-incubation }}-\left(\mathrm{DFe}_{\text {initial }}+\mathrm{DFe}_{\text {blank }}\right)$, and $\Delta \mathrm{O}_{2}=\mathrm{O}_{2 \text { pre-incubation }}-$ $599 \mathrm{O}_{2}$ post-incubation (initial, pre-incubation, and post-incubation terms are illustrated in Fig. 1a). The 600 error in $R_{\mathrm{Fe} / \mathrm{O} 2}$ was calculated by propagating the uncertainties from $\Delta \mathrm{DFe}$ and $\Delta \mathrm{O}_{2}$.

601 The Fe/C regeneration ratio $\left(R_{\mathrm{Fe} / \mathrm{C}} ; \mu \mathrm{mol} / \mathrm{mol}\right.$; Fig. $\left.3 \mathrm{c}\right)$ was calculated as: $R_{\mathrm{Fe} / \mathrm{C}}=R_{\mathrm{Fe} / \mathrm{O} 2} /$ 6020.69 , where 0.69 is a $\mathrm{C}: \mathrm{O}_{2}$ conversion factor (i.e., $\left.117 / 170\right)^{56}$. Note that different conversion 603 factors can be used to convert the oxygen-based remineralization rate to carbon (discussed in 604 detail in ref. $^{22}$ ).

605 Particulate fluxes were expressed as concentrations to permit cross-comparison between 606 sites in which different collection times were employed (Supplementary-Table 1). Pre607 incubation particulate Fe, $\mathbf{P}$, and OC concentrations correspond to the sum of the post608 incubation particulate concentration, plus the concentration of the respective element released 609 into the dissolved phase (i.e., $\Delta \mathrm{DFe}, \Delta \mathrm{PO}_{4}\left(=\mathrm{PO}_{4}\right.$ post-incubation $-\mathrm{PO}_{4}$ initial $)$, and $\Delta \mathrm{OC}\left(=\Delta \mathrm{O}_{2} \times\right.$ 610 0.69), respectively).

611 The replenishment rate of Fe $\left(\% \mathrm{~d}^{-1}\right.$; Supplementary-Table 2$)$ was calculated as: $(\Delta \mathrm{DFe} /$

$\left.612 \mathrm{PFe}_{\text {pre-incubation }}\right) \times 100 / \Delta \mathrm{t},(\Delta \mathrm{t}$ corresponds to the incubation time $)$. The error was calculated 613 by propagating the uncertainties from $\triangle \mathrm{DFe}$ and $\mathrm{PFe}_{\text {pre-incubation. }} \mathrm{P}$ and $\mathrm{C}$ replenishment rates 614 were calculated in the same way.

615 Quantification of the lithogenic and biogenic fractions of sinking PFe has large 616 uncertainties. Twining et al. ${ }^{15}$ reported a 2.3 and 4.4-fold increase in the Fe/P and Fe/S (proxy 617 of $\mathrm{Fe} / \mathrm{C}$ ) ratios of sinking diatom by $200 \mathrm{~m}$ depth, respectively, highlighting difficulties in 618 estimating the biogenic fraction of sinking PFe from surface cell quotas. An alternative 619 approach is to estimate the lithogenic fraction of PFe by using the Fe/Al ratio. However, the 620 present study encompasses different regions where lithogenic material has different Fe and Al 
621 compositions. In addition, dissolution/scavenging of $\mathrm{Fe}$ and $\mathrm{Al}$ differ during particle 622 settling $^{60}$, altering their pre-depositional $\mathrm{Fe} / \mathrm{Al}$ ratio. Thus, lithogenic $\mathrm{PFe}$ estimated at 623 ALG/ION using a Saharan dust end-member Fe/Al ratio ${ }^{59}$ is systematically higher than total 624 PFe. In contrast, suspended particles collected at ALG/ION had a Fe/Al ratio comparable to 625 the crustal Fe/Al ratio $^{58}$ (Supplementary-Fig. 3). Thus, the crustal Fe/Al molar ratio was used 626 to estimate biogenic and lithogenic PFe components in Fig. 2 and 3c. For the remainder of the 627 study, the PFe/POC molar ratio (hereafter termed Fe/C) of the intercepted particles (Fig. 3) 628 was used as a proxy for the composition of the PFe flux. In using this approach, we consider 629 POC and PFe as proxies of biogenic (algal/detrital) and lithogenic PFe, respectively ${ }^{9}$. This

630 ratio increases when the relative proportion of lithogenic Fe increases, and vice-versa. We 631 acknowledge that the biogenic $\mathrm{Fe} / \mathrm{C}$ ratio differs between Fe-limited and Fe-replete areas, 632 however, we believe that this approach is relatively robust when considering such contrasting 633 sites.

634

635 Ancillary biogeochemical information - Surface chlorophyll- $a$ was derived from MODIS636 Aqua. The $4 \mathrm{~km}$ resolution eight-day composite images were averaged over the 2003-2017 637 period (due to extensive subantarctic cloud-cover) for a $1^{\circ} \times 1^{\circ}$ box centered at each site. At 638 SAZ, MODIS chlorophyll- $a$ concentrations were corrected using an improved regional 639 algorithm ${ }^{61}$.

640 Monthly estimates of total (wet + dry) dust deposition annually averaged were obtained using 641 an atmospheric model (CAM4-BAM, case $\mathrm{C} 4 \mathrm{fn})^{23}$ run for 30 years, of which we considered 642 the last 10 years, with a spatial resolution of $0.9^{\circ} \times 1.25^{\circ}$.

643

644 The PISCES biogeochemical model experiment - PISCES ${ }^{62,63}$ is a relatively complex 645 general ocean circulation and biogeochemistry model with two PFe pools (large and small) 
646 characterized by different sinking rates, and two analogous POC size classes sourced from the

647 'mortality' of organic Fe and C pools. Uncomplexed DFe is subjected to scavenging, while 648 colloidal iron undergoes coagulation losses, both of which augment two PFe size classes.

649 Scavenging rate depends on the particle abundance, including the lithogenic PFe pool (based

650 on the dust input at the surface and a simple sinking speed). Subsurface dissolution of 651 lithogenic PFe occurs with a $\sim 500 \mathrm{~m}$ length-scale, a sinking rate of $2 \mathrm{~m} \mathrm{~d}^{-1}$, and a reduced 652 solubility. PFe remineralization takes into account changes in particle size and lability due to 653 bacterial solubilization via reactivity continuum ${ }^{64}$.

654 We conducted a range of different simulations with PISCES aimed at addressing the first655 order influence of lithogenic particles (i.e., dust) on $R_{\mathrm{Fe} / \mathrm{O} 2}$. Building this parameterization on 656 dust has many advantages. Indeed, biogenic $\mathrm{Fe}$ is a complex pool (detritus/algal) 657 characterized by different cell quotas ${ }^{65}$, while dust supply is a well-established component ${ }^{4}$ 658 that does not require explicit modelling of extra pools and can be incorporated more widely 659 into models. In the model, $R_{\mathrm{Fe} / \mathrm{O} 2}$ is derived by dividing the annually integrated 660 remineralization flux of iron from $\mathrm{PFe}$ by the $\mathrm{O}_{2}$ consumption during remineralization at each 661 model grid cell. We conducted a set of sensitivity experiments where PFe remineralization 662 was modulated by the lithogenic particle concentration at each model grid cell. This 663 modulator ( $M$, an unitless quantity) is a function of the lithogenic particle concentration: $M=$ $6641-[$ lithogenic particles / (lithogenic particles $+\mathrm{kd})] . M$ has a range of different sensitivities $665\left(\mathrm{kd}=0.1,1,5\right.$ and $\left.10 \mu \mathrm{g} \mathrm{m}^{-3}\right)$. To avoid double accounting, Fe scavenging by dust included in 666 PISCES $^{62}$ was switched off. We then ran for 500 years experiments as well as a 500 -year 667 model run in which PFe remineralization was left unchanged (Supplementary-Fig. 4a). We 668 then compared the range of $R_{\mathrm{Fe} / \mathrm{O} 2}$ outputs from each experiment with the local lithogenic PFe 669 concentrations (Fig. 5a), which showed that $\mathrm{kd}=0.1 \mu \mathrm{g} \mathrm{m} \mathrm{m}^{-3}$ was the most realistic as it 670 reproduced the inverse relationship observed between $R_{\mathrm{Fe} / \mathrm{O} 2}$ and the lithogenic $\mathrm{PFe}$ 
671 concentrations (Fig. 3b). To minimize the impact of high iron inputs (e.g., near shelves), only

672 offshore regions $\left(>3000 \mathrm{~m}\right.$ depth; $\left.30^{\circ} \mathrm{S}-30^{\circ} \mathrm{N}\right)$ were considered. Finally, the impact of this

673 new parameterization on DFe inventories, vertical DFe distribution, and surface iron-driven

674 processes was investigated.

675

676 Exploration of caveats - Our approach comes with some caveats, most of which were 677 identified and discussed in ref. ${ }^{22}$. Here, we discuss potential biases that may have affected Fe 678 cycling within the TM-RESPIRE. Specifically, we acknowledge that the pre-concentration of 679 particles in a $1.6 \mathrm{~L}$ chamber, along with the widely-differing downward fluxes (Fig. 2), may 680 have influenced the DFe replenishment rates.

681 The potential effects of this experimental bias, related to the need of concentrating particles 682 and to the contrasting sites, were tested via in vitro incubation experiments (Supplementary683 Fig. 5). The rationale, method, and conclusions are described in the Figure caption. Results 684 from these experiments suggest that during the $<48 \mathrm{~h}$ incubation within the TM-RESPIRE, 685 the limited loss of DFe by adsorption onto walls/particles was not significantly influenced by 686 the particle concentration, and by the surface-area-to-volume (SA:Vol) ratio of the incubation 687 bottles $\left(0.31-0.59 \mathrm{~cm}^{-1}\right)$. This later finding allows us to conclude that a different SA:Vol ratio 688 of the TM-RESPIRE incubation chamber $\left(0.57 \mathrm{~cm}^{-1}\right)$ would not have changed our 689 conclusions.

690 In our study, the concomitant decreases in DFe replenishment and particle volume 691 concentrations observed with depth at ALG/ION (Supplementary-Tables 2 and 4) do not 692 support a particle concentration effect on the replenishment of Fe. This experimental bias, that 693 would act to lower DFe concentration, has mainly been observed during dust dissolution 694 experiments ${ }^{66}$. This effect is likely offset in incubations with mixed biogenic/lithogenic 695 particles (along with the associated bacterial communities) by the concurrent release of Fe- 
696 binding ligands (which increased on average by a factor $>2$ in our study; Supplementary-

697 Table 3). Consistent with the conclusions of this study, the particle composition and/or 698 bacterial communities, rather than experimental parameters, appear to be the primary control 699 of the DFe replenishment rate in these in vitro experiments.

701 Data availability - Modis Chl-a concentrations (ALG and ION sites) were obtained with the 702 Giovanni online data system, developed and maintained by the NASA GES DISC. MODIS

703 Chl-a concentrations corrected using an improved regional algorithm for the Southern Ocean 704 (SAZ site) are publicly available via the Australian Integrated Marine Observing System 705 (IMOS) Ocean Portal (www.imos.org.au). Following publication, the dataset generated and 706 analysed during the current study (mostly available in the Supplementary Information section) 707 will be made available (i.e. open access) through the IMAS/UTAS data portal 708 (http://www.imas.utas.edu.au/data).

709

710 Code availability - The NEMO-PISCES model we use in this work is freely available 711 (http://www.nemo-ocean.eu/) under the CeCILL free software licence 712 (http://www.cecill.info/index.en.html). We used a modified version of the PISCES 713 biogeochemical model. These modifications concern the representation of the particulate iron

714 remineralization and this is not yet present in the freely available NEMO release but will be 715 provided upon contacting A.T.

716

\section{References}

718 36. Zúñiga, D., et al. Particulate organic carbon budget in the open Algero-Balearic Basin 719 (Western Mediterranean): Assessment from a one-year sediment trap experiment. Deep $720 \quad$ Sea Res. Part I 54, 1530-1548 (2007). 
37. Stavrakakis, S., et al. Downward fluxes of sinking particulate matter in the deep Ionian Sea (NESTOR site), eastern Mediterranean: seasonal and interannual variability. Biogeosciences 10, 7235 (2013).

38. Rigual-Hernández, A. S., Trull, T. W., Bray, S. G., \& Armand, L. K. The fate of diatom valves in the Subantarctic and Polar Frontal Zones of the Southern Ocean: Sediment trap versus surface sediment assemblages. Palaeogeogr. Palaeoclimatol. Palaeoecol. 457, 129-143 (2016).

39. Eriksen, R., et al. Seasonal succession of phytoplankton community structure from autonomous sampling at the Australian Southern Ocean Time Series (SOTS) observatory. Mar. Ecol. Prog. Ser. 589, 13-31 (2018).

40. Li, F., Ginoux, P., \& Ramaswamy, V. Distribution, transport, and deposition of mineral dust in the Southern Ocean and Antarctica: Contribution of major sources. J. Geophys. Res. 113, D10207 (2008).

41. Ebersbach, F., Trull, T. W., Davies, D. M., \& Bray, S. G. Controls on mesopelagic particle fluxes in the Sub-Antarctic and Polar Frontal Zones in the Southern Ocean south of Australia in summer-Perspectives from free-drifting sediment traps. Deep Sea Res. Part II 58, 2260-2276 (2011).

42. Bowie, A. R. et al. Biogeochemical iron budgets of the Southern Ocean south of Australia: Decoupling of iron and nutrient cycles in the subantarctic zone by the summertime supply. Glob. Biogeochem. Cycles, 23, GB4034 (2009).

43. D'Ortenzio, F., et al. Seasonal variability of the mixed layer depth in the Mediterranean Sea as derived from in situ profiles. Geophys. Res. Lett. 32, L12605 (2005).

44. Guerzoni, S., et al. The role of atmospheric deposition in the biogeochemistry of the Mediterranean Sea. Progr. Oceanogr. 44, 147-190 (1999). 
45. D'Ortenzio, F., \& Ribera d'Alcalà, M. On the trophic regimes of the Mediterranean Sea: a satellite analysis. Biogeosciences 6, 139-148 (2009).

46. Ramondenc, S., et al. An initial carbon export assessment in the Mediterranean Sea based on drifting sediment traps and the Underwater Vision Profiler data sets. Deep Sea Res. Part I 117, 107-119 (2016).

47. McDonnell, A. M., Boyd, P. W., \& Buesseler, K. O. Effects of sinking velocities and microbial respiration rates on the attenuation of particulate carbon fluxes through the mesopelagic zone. Glob. Biogeochem. Cycles 29, 175-193 (2015).

48. Lamborg, C. H., et al. The flux of bio-and lithogenic material associated with sinking particles in the mesopelagic "twilight zone" of the northwest and North Central Pacific Ocean. Deep Sea Res. Part II 55, 1540-1563 (2008).

49. Bonnet, S., \& Guieu, C. Atmospheric forcing on the annual iron cycle in the western Mediterranean Sea: A 1-year survey. J. Geophys. Res. Oceans 111, C09010 (2006).

50. Rees, C., et al. Methods for reproducible shipboard SFA nutrient measurement using RMNS and automated data processing. Limnol. Oceanogr. Methods 17, $25-41$ (2019).

51. Aminot, A., \& Kérouel, R. Dosage automatique des nutriments dans les eaux marines: méthodes en flux continu, Ed. Ifremer, Méthodes d'analyse en milieu marin (2007).

52. Croot, P. L. \& Johansson, M. Determination of Iron Speciation by Cathodic Stripping Voltammetry in Seawater Using the Competing Ligand 2-(2-Thiazolylazo)-p-cresol (TAC). Electroanalysis 12, 565-576 (2000).

53. Planquette, H., \& Sherrell, R. M. Sampling for particulate trace element determination using water sampling bottles: methodology and comparison to in situ pumps. Limnol. Oceanogr. Methods 10, 367-388 (2012).

54. Steinberg, D. K., et al. Bacterial vs. zooplankton control of sinking particle flux in the ocean's twilight zone. Limnol. Oceanogr. 53, 1327-1338 (2008). 
55. LeCleir, G. R., DeBruyn, J. M., Maas, E. W., Boyd, P. W., \& Wilhelm, S. W. Temporal changes in particle-associated microbial communities after interception by nonlethal sediment traps. FEMS microbiol. Ecol. 87, 153-163 (2014).

56. Anderson, L. A., \& Sarmiento, J. L. Redfield ratios of remineralization determined by nutrient data analysis. Glob. Biogeochem. Cycles 8, 65-80 (1994).

57. Reinthaler, T., et al. Prokaryotic respiration and production in the meso-and bathypelagic realm of the eastern and western North Atlantic basin. Limnol. Oceanogr. 51, 1262-1273 (2006).

58. Wedepohl, K. H. The composition of the continental crust. Geochim. Cosmochim. Acta 59, 1217-1232 (1995).

59. Guieu, C., Loÿe-Pilot, M. D., Ridame, C., \& Thomas, C. Chemical characterization of the Saharan dust end-member: Some biogeochemical implications for the western Mediterranean Sea. J. Geophys. Res. 107, ACH-5 (2002).

60. Baker, A. R., Adams, C., Bell, T. G., Jickells, T. D., \& Ganzeveld, L. Estimation of atmospheric nutrient inputs to the Atlantic Ocean from $50^{\circ} \mathrm{N}$ to $50^{\circ} \mathrm{S}$ based on largescale field sampling: Iron and other dust-associated elements. Glob. Biogeoch. Cycles 27, $755-767$ (2013).

61. Johnson, R., Strutton, P. G., Wright, S. W., McMinn, A., \& Meiners, K. M. Three improved satellite chlorophyll algorithms for the Southern Ocean. J. Geophys. Res. 118, 3694-3703 (2013).

62. Aumont, O., Ethé, C., Tagliabue, A., Bopp, L., \& Gehlen M. PISCES-v2: an ocean biogeochemical model for carbon and ecosystem studies, Geoscientific Model Development, 8, 2465-2513 (2015).

63. Völker, C., \& Tagliabue, A. Modeling organic iron-binding ligands in a three-dimensional biogeochemical ocean model, Mar. Chem., 173, 67-77 (2015). 
795 64. Aumont, O., et al. Variable reactivity of particulate organic matter in a global ocean 796 biogeochemical model, Biogeosciences, 14, 2321-2341 (2017).

797 65. Boyd, P. W. et al. Why are biotic iron pools uniform across high-and low-iron pelagic 798 ecosystems?. Glob. Biogeoch. Cycles 29, 1028-1043 (2015).

799 66. Bonnet, S., \& Guieu, C. Dissolution of atmospheric iron in seawater. Geophys. Res. Lett. 800 31, L03303 (2004). 
Particle interception $\quad$ Particle incubation
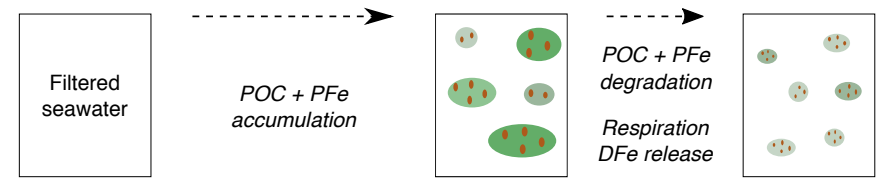

Initial

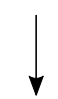

Pre-Incubation

$D F e$ release
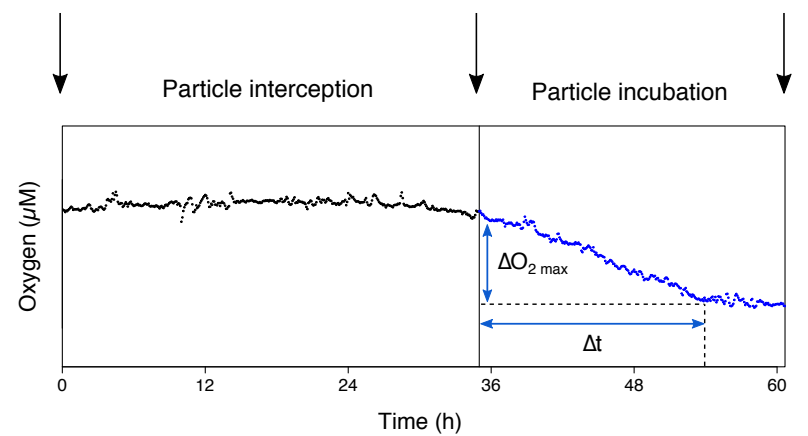

c
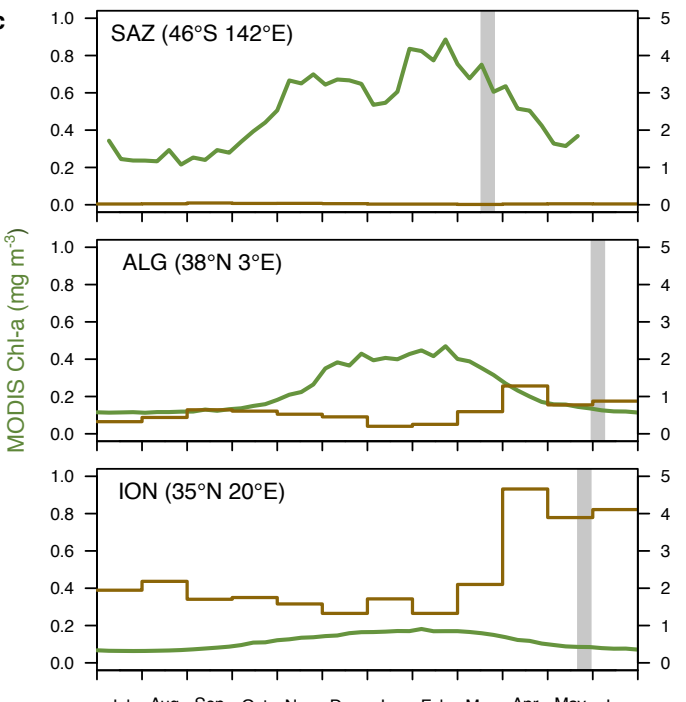

Jul Aug Sep Oct Nov Dec Jan Feb Mar Apr May Jun 

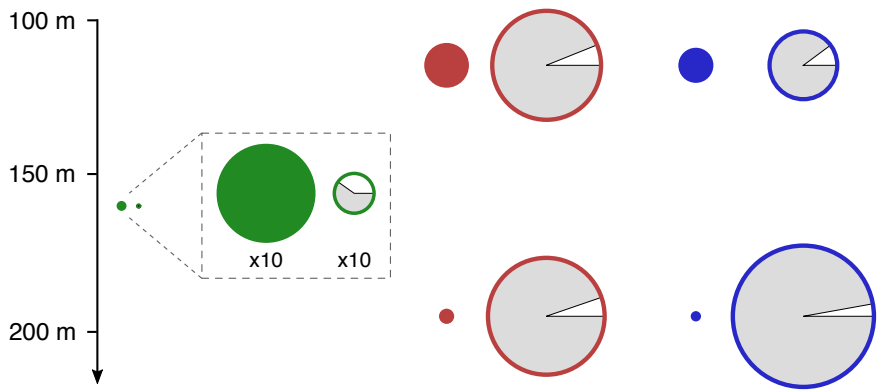
$\mathbf{a}$

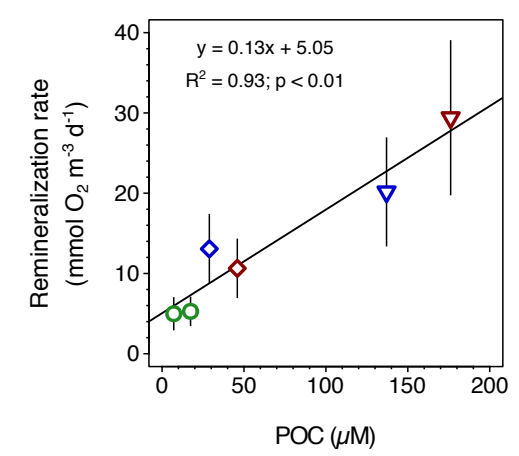

b

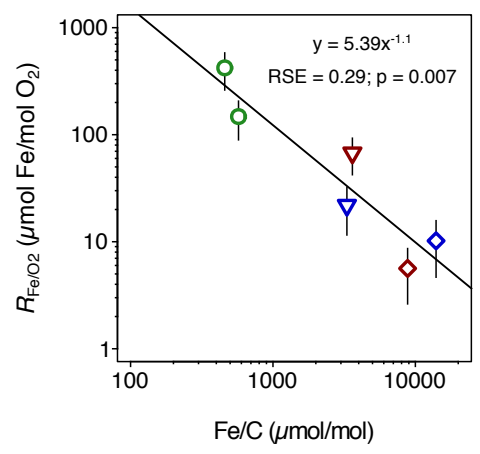

C

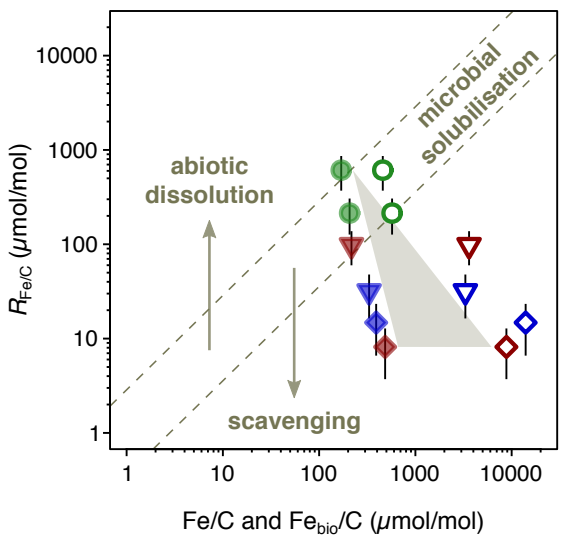



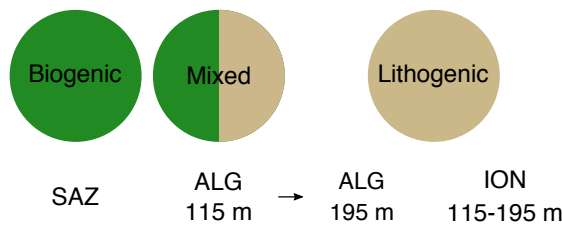

\section{DFe release} $\left(\mu \mathrm{mol} \mathrm{Fe} / \mathrm{mol} \mathrm{O}_{2}\right)$

$\mathrm{DFe}_{\text {litho }}{ }^{(1)}$ (\% of $\triangle \mathrm{DFe}$ )

$0.01 \%$

$0.5 \% \quad \rightarrow \quad 17 \%$

$2-9 \%$

Post-incubation L* (2)

0.43

0.25

$\rightarrow \quad 0.18$

$0.21-0.12$

Potential lithogenic scavenging ${ }^{(3)}$ ( $\%$ of $\left.\triangle \mathrm{DFe}\right)$

$0.3 \%$

$5 \%$

$\rightarrow \quad 170 \%$

$30-130 \%$

PFe attenuation ${ }^{(4)}$

$$
(+++)
$$

(1) Estimates based on a dissolution rate of $0.018 \mathrm{nmol} \mathrm{mg}^{-1} \mathrm{dust}^{-1(30)}$

(2) $L^{*}$ corresponds to the excess of ligands over DFe after the incubation phase

(3) Estimates based on a scavenging ratio of DFe on dust of $0.37 \mathrm{nmol} \mathrm{mg} \mathrm{mg}^{-1(18)}$

(4) At SAZ, estimate based on the balance between $\mathrm{DFe} / \mathrm{L}$ release and scavenging 
